\title{
Özofagusun leiomyomaları
}

\author{
Leiomyomas of esophagus
}

Tülay DİKEN ALLAHVERDİ, Neşet KÖKSAL, Barlas SÜLÜ, Turgut ANUK, Yusuf GÜNERHAN

Kafkas Üniversitesi Tip Fakültesi Genel Cerrahi Anabilim Dah, Kars

\begin{abstract}
Giriş ve Amaç: Özofagusun leiomyomları özofagusun en sık görülen benign tümörleridir.Bu çalışmanın amacı; 18 aylık bir dönemde cerrahi tedavi yapılan altı hastanın sunumudur. Gereç ve Yöntem: Epidemiyolojik veri, semptomlar, diagnostik, muayeneler, yerleșim, histopatolojik bulgular ve cerrahi rezeksiyonun sonuçları değerlendirildi. Bulgular: Ortalama yaşı kırkdokuz olan iki erkek ve dört kadın ameliyat edildi. Uç olguda leiomyoma özofagusun orta bölümünde yerleşirken, üç vakada tümör alt özofagus yerleşimliydi. Beş hastada disfaji gibi leiomyoma ilișkili semptomlar vardı. Uç hastada lezyona enükleasyon sağ posterolateral torakotomi ile yapıldı. Iki hastada laparotomi ile enükleasyon uygulandi. Bir hasta endoskopik mukozal rezeksiyon ile tedavi edildi. Ortalama rezeke edilen tümör çapı $4 \mathrm{~cm}$ idi. Hiçbir olguda malignite ve metastaz saptanmadi. Postoperatif morbidite ve mortalite saptanmadı. Tartışma: Özofagus leiomyoma için cerrahi enükleasyon güvenli, etkili olarak düşünüldü. Endoskopik submukozal rezeksiyon küçük boyutlu özofageal leiomyomalı bazı hastalar için uygulanabilir ve minimal invaziv tedavi yöntemi olarak görünmektedir
\end{abstract}

Anahtar kelimeler: Leiomyoma, özofagus, enükleasyon, endoskopik submukozal rezeksiyon

\section{GİRİS}

Leimyomalar özofagusun en slk görülen benign tümörleridir. Otopsi serilerinde \%0,05 ile 5,1 oranında saptanmıştır. Ilk olarak 176l'de Morgagni tarafindan tanımlanan leiomyomlar, düz kas kaynaklı hücre tümörleri olup özofagusun muskularis propria tabakasından köken almaktadırlar. Leiomyomlar genellikle küçük boyutlarda ve asemptomatik seyirlidirler. Boyutları büyüdükçe, neden oldukları semptomlarla ya da insidental olarak saptanırlar $(1,2)$.

Özofageal leiomyomların tedavisinde önerilen cerrahi işlem enükleasyondur. Nadiren rezeksiyon gerekir. Cerrahi, tümör boyutu ve sayısına göre açı cerrahi ya da minimal invaziv teknikler ile yapılabilir. Üç cm'nin altındaki leiomyomlar endoskopik submukozal rezeksiyonla (EMR) çıkarılabilir. Aynı zamanda torasik özofagusun üst 2/3 kısımında lokalize lezyonlarda video yardımlı torakoskopik cerrahi uygulanabilir (3-6).

\section{GEREÇ VE YÖNTEM}

Kafkas Üniversitesi Tip Fakültesi Genel Cerrahi Anabilim Dalında 2012-2013 ylları arasında disfaji ve retrosternal yan-
Background and Aims: Leiomyomas of the esophagus are the most frequent benign tumors of esophagus. The aim of this study is to describe 6 patients with esophageal leiomyomas who underwent surgical treatment during a 18-month period. Materials and Methods: Epidemiological data, symptoms, diagnostic examinations, location, histopathological findings and the results of surgical resection were assessed. Results: Two men and 4 women, mean age of 49 years, underwent surgery. In 3 cases the tumor was located in the lower esophagus, while in the other 3 cases, the leiomyoma was found at the middle part of esophagus. Five patients had symptoms related to the leiomyoma such as dysphagia. Three patients underwent a right postolateral thoracotomy with enucleation of the lesion. Two patients underwent laparatomy with enucleation of the lesion. One patient was treated by endoscopic submucosal resection (EMR). The mean diameter of the resected tumors were $4 \mathrm{cms}$. No cases of malignancy or recurrence was detected. Postoperative morbidity and mortality did not occur. Conclusion: Surgical enucleation is considered as a safe and effective procedure for esophageal leiomyoma. Endoscopic submucosal resection appears to be a feasible and minimally invasive treatment for some patients with little esophageal leiomyomas.

Key words: Leiomyoma, esophagus, enucleation, endoscopic submucosal resection

ma hissi nedeni ile yapilan üst gastrointestinal sistem (GIS) endoskopisi sonucu özofagusta kitle saptanıp, cerrahi tedavi uygulanan ve histopatolojik değerlendirmesi leiomyoma saptanan 6 olgunun dosya kayitları retrospektif olarak incelendi. Hastaların yaş, cinsiyet, semptom, tümörlü özofagus segmenti, tümör çapı, uygulanan cerrahi tedavi ve sonuçları, ameliyat sonrası komplikasyonlar kaydedildi. Hastaların ilk yıl takipleri, postoperatif 6 . ayda üst GiS endoskopisi ve 1 . yıldaki semptomatik hastalarda üst GIS endoskopisi ve torako abdominal tomografi ile yapıldı.

\section{BULGULAR}

Ikisi erkek, 4'ü kadın altı hastanın ortalama yaşı 44 48 (3157) idi. Hastaların beşinin hastaneye başvuru şikayeti disfaji ve retrosternal yanma hissi ve reflü iken, 1 hastada da bulantı ve kusma saptandı. Hastaların tamamına üst GIS endoskopisi ve kitle saptanması üzerine de biyopsi ve torako abdominal kontrastlı tomografi yapıldı (Resim 1-2). Tümörlerin yerleşim yeri 23. cm'den 40. cm'ye kadar farklı segmentlerde tespit edilirken, en küçük tümör çapı $2 \mathrm{~cm}$, en büyük tümör çapı 
ise $6 \mathrm{~cm}$ olarak saptandı. Lezyonların tümör çapına göre dağılımı Tablo l'de verilmiştir. Hastaların 3'üne sağ posterolateral torakotomi ile, 2'sine laparotomi ile enükleasyon ve l'ine de endoskopik submukozal rezeksiyon uygulandı (Tablo 2). Intraoperatif ve postoperatif histopatolojik değerlendirmede lenf nodu metastazı ve uzak organ metastazı mevcut değildi. Hastaların ortalama $12 \pm 8.48$ ay (6-18) olan takiplerinde, hiçbir hastada komplikasyon, morbidite ve mortalite gelişmedi.

\section{TARTIȘMA}

Leimyom özofagusun en yaygın görülen benign neoplazmıdır. Erkeklerde kadınlara göre 2 kat daha fazla görülürken, 3.-4. dekatlar arasında insidansı pik yapar. Genellikle farklı büyüklüklerde, yuvarlak ve oval biçimli, düzgün kenarlı asemptomatik lezyonlar olup, sıklıkla insidental saptanırlar. Bazen lobüle olup, özofagus duvarını çepeçevre sarabilirler. Düzgün kenarlı olmalarına rağmen her zaman kapsüllü olmayabilirler. Leiomyomlar siklıkla özofagusun orta ve alt $1 / 3^{\prime}$ lük

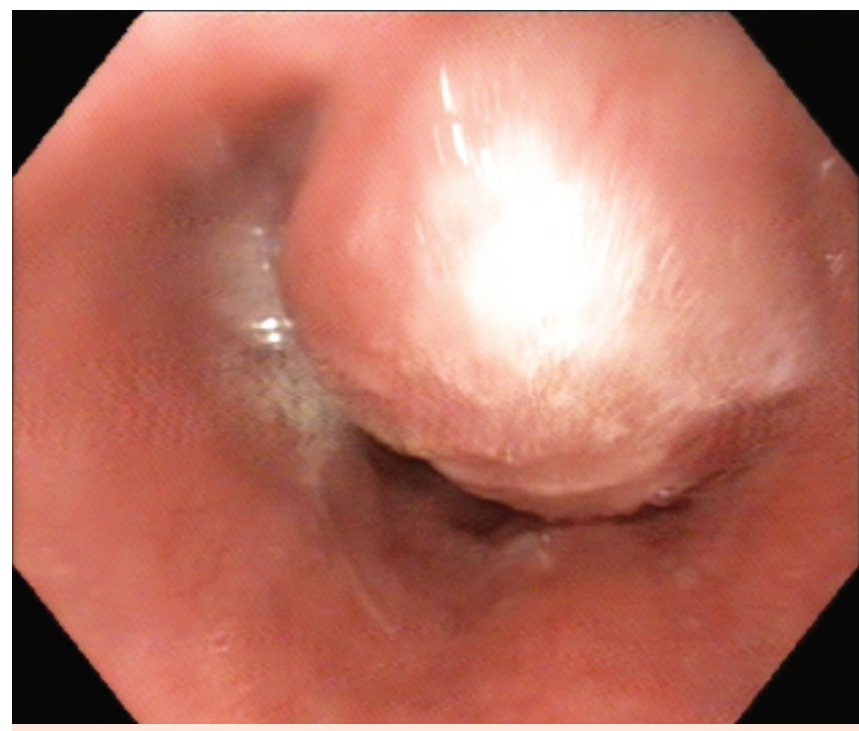

Resim 1. Leiomyomanın endoskopik görünümü.

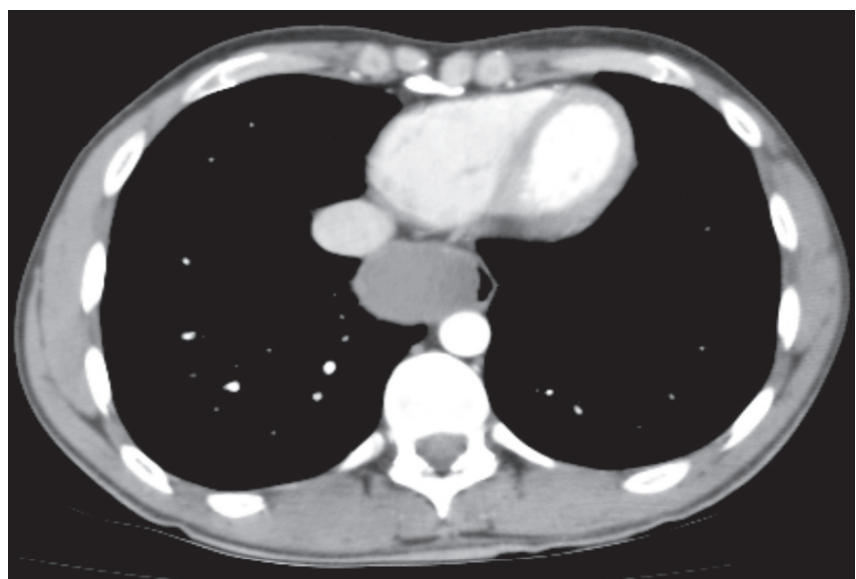

Resim 2. Leiomyomanın toraks tomografi görüntüsü. kısımında ve düzgün sınırlı, submukozal kitle şeklinde ortaya çıkarlar $(1,2)$. Bizim çalışmamızda opere edilen 6 hastamızın 3'ünde tümöral kitlenin 39 ve 40 cm'de, 3'ünde $23-28$ cm'ler arasında saptandığı gözlenmiştir. En sık karşılaşılan semptomlar; disfaji, nonspesifik göğüs ağrısı ve retrosternal ağrı, daha seyrek olarak da regürjitasyon, epigastrik hassasiyet, nefes darlığı ve kilo kaybıdır. Hastalarımızda en sık disfaji ve retrosternal ağrı gözlenirken, en büyük tümör çapına ulaşmış olan hastamızda şiddetli bulantı ve kusma gözlendi.

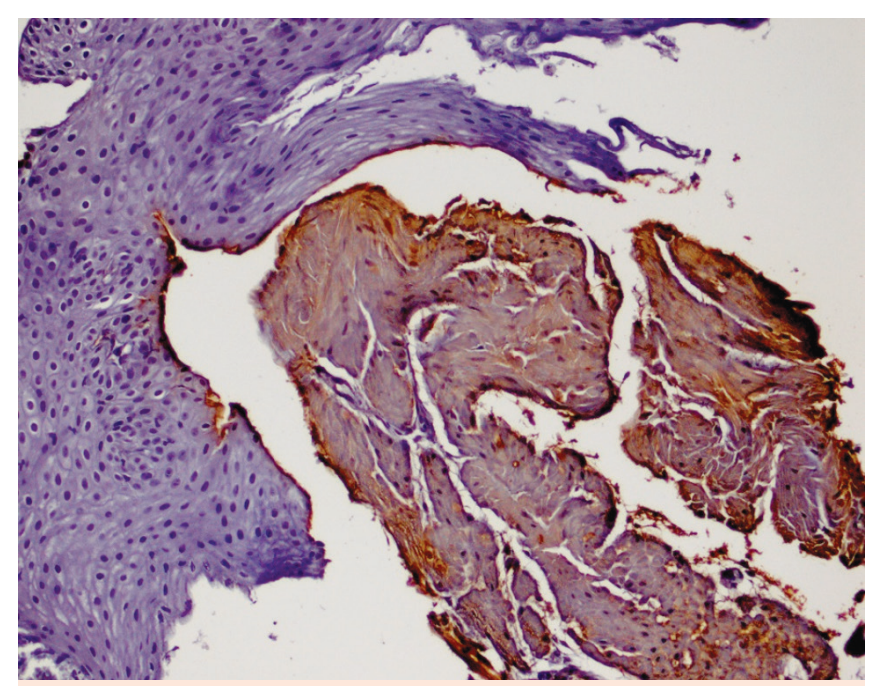

Resim 3. Leiomyomanın patolojik bulguları.

Tablo 1. Tümör lokalizasyonu ve çapı (Lokalizasyonlar endoskopik olarak kesici dişlerden itibaren hesaplanmıştır. Çaplar ise çıkarılan piyeslerden yapılan ölçümlerdir.)

\begin{tabular}{llcl} 
Şikayet & Yerleşim Yeri & Cinsiyet & Tm çapı \\
$\begin{array}{l}\text { Disfaji, retrosternal } \\
\text { yanma }\end{array}$ & Özofagus $23 \mathrm{~cm}$ & $\mathrm{~K}$ & $3 \mathrm{~cm}$ \\
$\begin{array}{l}\text { Disfaji, retrosternal } \\
\text { yanma }\end{array}$ & Özofagus $24 \mathrm{~cm}$ & $\mathrm{~K}$ & $5 \mathrm{~cm}$ \\
$\begin{array}{l}\text { Disfaji, retrosternal } \\
\text { yanma }\end{array}$ & Özofagus $28 \mathrm{~cm}$ & $\mathrm{E}$ & $3 \mathrm{~cm}$ \\
\hline $\begin{array}{l}\text { Disfaji, retrosternal } \\
\text { yanma }\end{array}$ & Özofagus $39 \mathrm{~cm}$ & $\mathrm{~K}$ & $2 \mathrm{~cm}$ \\
$\begin{array}{l}\text { Bulantı, kusma } \\
\text { Özofagus } 39 \mathrm{~cm}\end{array}$ & $\mathrm{E}$ & $6 \mathrm{~cm}$ \\
\hline $\begin{array}{l}\text { Disfaji, retrosternal } \\
\text { yanma }\end{array}$ & Özofagus $40 \mathrm{~cm}$ & $\mathrm{~K}$ & $3.5 \mathrm{~cm}$ \\
\hline
\end{tabular}

Tablo 2. Uygulanan cerrahi tedavi

Yapılan İşlem No

Sağ posterolateral torakotomi ile enükleasyon

Endoskopik submukozal rezeksiyon

Laparatomi ile enükleasyon

2 
Tanı özofagogram, özofagoskopi, bilgisayarlı tomografi ve manyetik rezonans görüntüleme ile konur. Özellikle özofagoskopide mukoza bütünlügünün korunmuş olması ve lümene doğru büyümüş düzgün sınırlı lezyon olması karakteristiktir $(1,2)$. Hastalarımızın tamamına üst GIS endoskopik biyopsi ile tanı konulmuş olup, preoperatif torako abdominal tomografi ile de periferik tutulumlar görüntülenmiştir. Tüm hastalarımızda tek odakta saptanan leiomyomların, literatürde, tek odakta olabildiği gibi, bazı multiple formlarının da olduğu bildirilmiştir (6).

Leiomyomalar için önerilen cerrahi tedavi enükleasyondur. Enükleasyon, lezyonun lokalizasyonu ve büyüklüğüne göre torakal, abdominal ya da endoskopik yoldan yapılabilir $(7,8)$. Cerrahi yaklaşıma karar vermede tümörün tek veya multiple oluşu, büyüklüğü ve lokalizasyonu yol göstericidir. En çok tercih edilen yöntemler geçmişten bugüne lezyonun yerine göre laparotomi veya torakotomi ile enükleasyondur. Bizim çalışmamızda da üç olguda torakotomi ve iki olguda laparotomi yapılarak, herhangi bir komplikasyon olmadan leiomyoma enükleasyonla çıkarıldı. Orta özofagusta bulunan leiomyomalar için torakoskopik yaklaşımla da enükleasyon yapılabilir. Torakoskopik yaklaşımlar (VATS) daha çok leiomyomların tek olduğu ve boyutunun 1-5 cm olduğu durumlarda tercih edilmektedir. Literatürde $6 \mathrm{~cm}$ 'den $10 \mathrm{~cm}$ 'ye kadar lezyonların VATS'la çıkarılabildiği bildirilmiştir $(8,9)$. Aynı zamanda bu yöntemle kardioözofageal bileşkenin $4 \mathrm{~cm}$ yukarısındaki leiomyomaların herhangi bir komplikasyon olmadan rahatlıkla çıkarılabileceği bildirilmiştir (10). Endoskopik yaklaşımlar da çeşitli lezyonların çıkarılmasında kullanılabilir. Leiomyomaların çıkarılmasında endoskopik olarak submukozal rezeksiyon tercih edilebilir. İki cm'nin altındaki lezyonlar bu yöntemle çıkarılabilirler. Fakat endoskopik yöntemlerde kanama, perforasyon ve tam rezeksiyon yapılamaması gibi bazı komplikasyonlar ortaya çıkabilir. Zhao ve ark.'nın yaptığı 26 hastalık çalışmada submukozal tümörler endoskopik olarak çıkarılmış ve herhangi bir patolojiye rastlanmamıştır (11). Huang ve ark. yaptıkları çalışmada ise 2 cm'nin altında boyutu olan 3 vaka endoskopik submukozal rezeksiyonla çıkarılmış ve herhangi bir komplikasyona rastlanmamıştır (12). Bizim çalışmamızda da bir vakada submukozal rezeksiyon uygulandı. Tümör çapı $2 \mathrm{~cm}$ idi. Herhangi bir komplikasyon olmadi.

\section{KAYNAKLAR}

1. Maggi G, Dei Poli M, Gaetini A, et al. Our experience in 6 cases of leiomyoma of the esophagus. Minerva Chirurgica 1981;36:1035-42.

2. Seremetis MG, Lyons WS, DeGusman VC, Peabody JW Jr. Leiomyomata of the Esophagus: an Analysis of 838 cases. Cancer 1976;38:2166-77.

3. Samphire J, Nafteux P, Luketich J. Minimally invasive techniques for resection of benign esophageal tumors. Semin Thorac Cardiovas Surg 2003;15:35-43

4. Van der peet DL, Berends FJ, Klinkemberg-Knol EC, Cuesta MA. Endoscopic treatment of benign esophageal tumors: case report of three patients. Surg Endosc 2001;15:1489.

5. Ousadden A, Bourdariat R, Poncet G, Boulez J. Esophageal leiomyoma. Six cases of video-assisted enucleation. Presse Med 2006;35:1649-55.

6. Pon M, Manger T, Wolf S, et al. Thoracoscopic enucleation of benign tumor of the esophagus under simultaneous flexible esophagoscopy. Surg Endosc 2000;14:1146-8.

7. Okugawa Y, Mohri Y, Toiyama Y, et al. Multiple solitary leiomyomas in the esophagus: report of a case. Surg Today 2011;41:563-7.

8. Pinheiro FA, Campos AB, Matos JR, Araripe DP. Videoendoscopic surgery for the treatment of esophagus' leiomyoma. Arq Bras Cir Dig 2013;26:234-7.

9. Hu X, Lee H. Complete thoracoscopic enucleation of giant leiomyoma of the esophagus: a case report and review of the literature. J Cardiothorac Surg 2014:9:34.

10. Li ZG, Chen HZ, Jin H, et al. Surgical treatment of esophageal leiomyoma located near or at the esophagogastric junction via a thoracoscopic approach. Dis Esophagus 2009;22:185-9.

11. Zhou PH, Yao LQ, Qin XY, et al. Endoscopic full-thickness resection without laparoscopic assistance for gastric submucosal tumors originated from the muscularis propria. Surg Endosc 2011;25:2926-31.

12. Huang ZG, Zhang XS, Huang SL, Yuan XG. Endoscopy dissection of small stromal tumors emerged from the muscularis propria in the upper gastrointestinal tract: Preliminary study. World J Gastrointest Endosc 2012:4:565-70. 